\title{
Czy teoria inteligentnego projektu posiada konsekwencje, dotyczące istnienia nadnaturalnego projektanta? Polemika z Elliottem Soberem *
}

Zauważyć można wyraźną ewolucję krytycznej postawy ewolucjonistów wobec teorii inteligentnego projektu, teorii ID, jak się ją w skrócie nazywa. Natężenie krytycyzmu nie ulega zmianie, stopniowej zmianie ulegają jednak argumenty, jakie się przedstawia. Początkowo uznawano, że teoria inteligentnego projektu jest starym kreacjonizmem w nowej szacie. ${ }^{1}$ Przyjmowano, że teoria ta mówi o projekcie Bożym, projekcie istoty nadprzyrodzonej, czyli że ma religijny charakter, podobnie jak tradycyjny kreacjonizm. ${ }^{2}$ skiego.

*Recenzent: Józef Zon, Katedra Biologii Teoretycznej Katolickiego Uniwersytetu Lubel-

${ }^{1}$ Dlatego polemiki z tą teorią ukazywały się przede wszystkim w czasopismach niefachowych. Por. Charles Krauthammer, „Let's Have No More Monkey Trials. To teach faith as science is to undermine both”, Time Aug. 01, 2005, http://tiny.pl/b9xt; Jerry CoYne, „The Case Against Intelligent Design. The Faith That Dare Not Speak Its Name", The New Republic 22 August, 2005, http://tiny.pl/b9x7; Richard Dawkins, „Creationism: God's Gift to the ignorant", The Times May 21, 2005; http://tiny.pl/b9x9.

${ }^{2}$ The Elie Wiesel Foundation For Humanity. Nobel Laureates Initiative, September 9, 2005, To: Kansas State Board of Education, http://media.ljworld.com/pdf/2005/09/15/ nobel_letter.pdf (jest to list 38 laureatów Nagrody Nobla protestujących przeciwko proponowanym zmianom w programie nauczania nauk przyrodniczych w szkołach publicznych stanu Kansas); Marshall Berman, „Intelligent Design: The New Creationism Threatens All of Science and Society", APS News October 2005, vol. 14, no. 9; http://tiny.pl/b9xc; Marshall 
Wiele podobnych twierdzeń można znaleźć w dawniejszych publikacjach. ${ }^{3}$ Na przykład Józef Życiński uważa Phillipa E. Johnsona za pewnego rodzaju fundamentalistę, który chce podporządkować współczesną biologię tezom ideologicznym. ${ }^{4}$

Później jednak do ewolucjonistów, przynajmniej niektórych, jakoś dotarły wielokrotnie powtarzane zapewnienia teoretyków projektu, jak to poniższe Behe'ego, że w istotny sposób różnią się oni od kreacjonistów, bo nie mówią, że projektantem był Bóg lub jakaś nadprzyrodzona istota.

[...] mój argument ogranicza się do samego projektu; mocno podkreślam, że nie jest to argument na istnienie życzliwego Boga, co charakteryzowało argument Paleya. ${ }^{5}$

Berman, „Intelligent Design Creationism: A Threat to Society - Not Just Biology”, The American Biology Teacher November/December 2003, vol. 65, no. 9, s. 646-648, http://tiny.pl/b9xf; Robert P. Crease, „Critical Point: Intelligent Design”, Physics World, October 2005 , vol. 18 , no. 10 , s. 19 .

${ }^{3}$ Por. Robert T. Pennock, Tower of Babel. The Evidence against the New Creationism, A Bradford Book, The MIT Press, Cambridge, Massachusetts - London, England 1999; artykuły autorów ewolucjonistycznych w: Robert T. PENNOCK (ed.), Intelligent Design Creationism and Its Critics. Philosophical, Theological and Scientific Perspectives, A Bradford Book, The MIT Press, Cambridge, Massachusetts - London, England 2001; Barbara C. Forrest and Paul R. Gross, Evolution and the Wedge of Intelligent Design: The Trojan Horse Strategy, Oxford University Press, Oxford 2003; Eugenie C. Sсотт, „The Creation/Evolution Continuum", NCSE Reports 1999, vol. 19, no. 4, s. 16-17, 23-25; Eugenie C. Sсотт, Evolution vs. Creationism. An Introduction, Greenwood Press, Westport, Connecticut - London 2004, rozdział 6, s. 113-133.

${ }^{4}$ Por. Józef ŻycińsKi, Bóg i ewolucja. Podstawowe pytania ewolucjonizmu chrześcijańskiego, Prace Wydziatu Filozoficznego 89, Towarzystwo Naukowe Katolickiego Uniwersytetu Lubelskiego, Lublin 2002, s. 34-36.

${ }^{5}$ Michael J. BeHE, „Współczesna hipoteza inteligentnego projektu. Łamanie reguł”, przeł. Dariusz Sagan, Na Początku... 2004, Rok 12, Nr 7-8 (183-184), s. 244 [244-266], http://tiny. $\mathrm{pl} / \mathrm{b} 9 \mathrm{mh}$. 
Z lektury czołowych teoretyków projektu okazuje się, że teoria ID nie tylko nie identyfikuje projektanta z Bogiem, ale twierdzi też, że taka identyfikacja - gdyby ktoś chciał ją przeprowadzić na podstawie samej tylko analizy przedmiotowej - jest niemożliwa, a przynajmniej bardzo trudna, w przeciwieństwie do ujrzenia faktu projektu, które jest względnie łatwe. ${ }^{6}$ Zresztą wiedza na temat projektanta nie jest potrzebna do ustalania faktu projektu. Wniosek o projekcie wyprowadza się na podstawie badań samego zaprojektowanego układu i jego szczególnych cech, takich jak nieredukowalna złożoność, które zdaniem zwolenników teorii ID wymagają inteligentnego przygotowania. ${ }^{7}$

Sposoby rozpoznawania projektu dotyczą wszystkich projektów, także pochodzących od człowieka. Nieprzypadkowo najbardziej znanym przykładem jest pułapka na myszy. Ale wnioskowanie o projekcie nie ogranicza się do wytworów człowieka. Od kilkudziesięciu lat mówi się na przykład o poszukiwaniach, znanych pod nazwą projekt SETI, sygnałów nadawanych przez cywilizacje kosmiczne. Jeśli jakieś układy biologiczne zostały rzeczywiście zaprojektowane, to istnieje wielu potencjalnych kandydatów do pełnienia funkcji projektanta. Bóg to tylko jedna, choć najczęściej brana pod uwagę, możliwość. Natura projektanta może być nawet zgodna z filozofią materialistyczną, bo może nim być cywilizacja kosmiczna lub podróżnicy w czasie. ${ }^{8}$ Teoretycy inteligentnego projektu wymieniają jeszcze inne mniej lub bardziej wiarygodne możliwości, ${ }^{9}$ ale dodają, że ustalenie natury projektanta wymaga informacji z dziedzin pozanaukowych. Żeby takie wnio-

\footnotetext{
${ }^{6}$ Michael J. Behe, Czarna skrzynka Darwina. Biochemiczne wyzwanie dla ewolucjonizmu, przeł. Dariusz Sagan, Biblioteka Filozoficznych Aspektów Genezy t. 4, Wydawnictwo MEGAS, Warszawa 2008, s. 218.

${ }^{7}$ Michael J. BEHE, „Filozoficzne zarzuty stawiane hipotezie inteligentnego projektu: odpowiedź na krytykę", przeł. Dariusz Sagan, Filozoficzne Aspekty Genezy 2004, t. 1, s. 131 [115-139], http://tiny.pl/b9mq.

${ }^{8}$ Michael J. Behe, „Faith and the Structure of Life” (oprac. z: Michael J. BeHE, „Faith and the Structure of Life", w: Gerard V., Bradley and Don DeMarco (eds.), Science and Faith, St. Augustine's Press, South Bend, Indiana, rozdział 2), http://tiny.pl/b9mt.

${ }^{9}$ BeHe, „Współczesna hipoteza...”, s. 244-245.
} 
skowanie przeprowadzić, trzeba dysponować dodatkowymi przesłankami, na przykład filozoficznymi lub teologicznymi. Sama identyfikacja projektanta nie jest zadaniem nauki, przynajmniej takiej, jaka obecnie istnieje. ${ }^{10}$

Ta stale powtarzana teza, że teoria inteligentnego projektu nie identyfikuje, kim jest projektant i dopuszcza także rozwiązania naturalistyczne, w końcu dotarła do ewolucjonistów zaangażowanych w polemikę $\mathrm{z}$ teorią ID. Być może pewną pomocą był fakt, że niektórzy zwolennicy inteligentnego projektu byli jednocześnie ateistami - można tu wymienić Freda Hoyle'a, Chandrę Wicramasinghe'ego, Francisa Cricka czy quasi-religijną sektę raelian. Przyklejanie teoretykom projektu „kreacjonistycznej łatki” jest więc nadużyciem. Najlepszy chyba historyk ruchu kreacjonistycznego, Ronald L. Numbers z University of Wisconsin, uznał, że etykietka kreacjonistyczna jest niewłaściwa, gdy mamy do czynienia z ruchem ID, i dodał, że używa się jej, gdyż jest to obecnie ,najłatwiejszy sposób zdyskredytowania teorii inteligentnego projektu". ${ }^{11}$

Zmuszeni przynajmniej do werbalnego uznania, ze teoria inteligentnego projektu nie jest tradycyjnie rozumianym kreacjonizmem, ewolucjoniści zaangażowani $\mathrm{w}$ spór $\mathrm{z}$ teorią ID przyjęli dwie różne taktyki krytykowania tej teorii. Jedna $\mathrm{z}$ nich polega na uznaniu, że zwolennicy ID nie są szczerzy i oszukują swoich słuchaczy i czytelników:

Obrońcy teorii inteligentnego projektu nie są skorzy do identyfikowania projektanta. Twierdzą, że nie musi on być Bogiem. Ale pomimo wypowiadanych aluzji, że mogą nim być pozaziemscy lub podróżujący w czasie biochemicy, nikogo nie wprowadzą w błąd, że mają na myśli kogoś innego niż Projektanta-Boga. ${ }^{12}$

\footnotetext{
${ }^{10}$ Behe, Czarna skrzynka Darwina..., s. 218.

${ }^{11}$ Cyt za: Richard N. Ostung, „«Intelligent design» gains attention in Ohio debate”, News - Star Shawnee, Oklahoma, Saturday, March 16, 2002, http://tiny.pl/b9m7.

${ }^{12}$ Eugenie C. ScotT and Glenn Branch, „Evolution: Just teach it”, USA Today 8/14/2005, http://tiny.pl/b9m9.
} 
Czyli niezależnie od tego, co powiedzą lub napiszą zwolennicy teorii inteligentnego projektu, i tak wiadomo, że kłamią i ukrywają prawdziwe poglądy. Ponieważ jednak taka taktyka pozwala każdemu przeciwnikowi przypisać dowolne poglądy i jednocześnie uniemożliwia rozstrzygnięcie sporu, pozwolę ją sobie zignorować.

Inną taktykę przyjął Elliott Sober, którego zdaniem istnieje wiele wersji teorii ID. Większość z nich ma większy lub mniejszy związek z religią i na poparcie tej tezy Sober cytuje wiele wypowiedzi ich zwolenników. Z pewnych względów, kontynuuje Sober, głównie po to, by obejść konstytucyjny zakaz propagowania religii w szkołach publicznych, wprowadzono wersję minimalistyczną teorii ID (Sober nazywa ją mini-ID), która już nie identyfikuje projektanta. Ale i ona według Sobera w pewnym wyspecyfikowanym przezeń sensie pociąga istnienie nadprzyrodzonego inteligentnego projektanta, ma więc prawdopodobnie konsekwencje religijne.

Zajmijmy się kolejnymi argumentami Sobera.

\section{Czy gra na skrzypcach jest częścią teorii względności?}

Sober cytuje kilka wypowiedzi zwolenników ID wskazujących, że wierzą oni w Boga. Jednak żadna z tych wypowiedzi i ich kontekst nie wskazują, by dotyczyły one teorii inteligentnego projektu. Johnson, oprócz tego, że zapoczątkował ruch ID, miał i ma parę innych pomysłów - jednym z nich był pogląd filozoficzny zwany realizmem teistycznym, a innym tzw. strategia klina. Pomysły te mają sporo wspólnego $\mathrm{z}$ teorią inteligentnego projektu, ale nie są z nią identyczne. Autorzy książki Of Pandas and People są zwolennikami teorii ID, ale sama książka została napisana wcześniej, zanim ruch ID powstał i zawiera różne poglądy, niekoniecznie powiązane $\mathrm{z}$ teorią ID. Nie wszystko, co przy różnych okazjach mówią i robią zwolennicy ID, obciąża konto tej teorii. Inaczej musielibyśmy uznać, że gra na skrzyp- 
cach jest częścią teorii względności, bo Einstein grywał na skrzypcach.

Nie ulega wątpliwości, że czołowi zwolennicy teorii ID (za wyjątkiem Davida Berlinskiego i Michaela Dentona) wierzą prywatnie w Boga, ale zdają sobie doskonale sprawę, że tych prywatnych wierzeń nie da się przenieść na płaszczyznę nauki:

[...] wierzę w życzliwego Boga i uznaję, że filozofia i teologia są zdolne rozszerzyć ten argument. Lecz w biologii naukowy argument na rzecz projektu nie sięga tak daleko. ${ }^{13}$

Wskazać też trzeba, że teoria ID, jak się ją teraz przedstawia, nie pojawiła się od razu w gotowej postaci, jak Atena $\mathrm{z}$ głowy Zeusa, ale przez pewien czas ewoluowała. Ewoluowała do tego stopnia, że nie jest już nawet dzisiaj pewne, czy jej charakterystyka podana przez Sobera jest poprawna (,odkryte w naturze nieredukowalnie złożone adaptacje są dziełem jednego lub większej liczby inteligentnych projektantów”). Dziś mówi się nie tyle o nieredukowalnej złożoności, co raczej o wyspecyfikowanej złożoności. To, jakie twierdzenia zwolenników ID będziemy uwzględniali w naszych analizach, zależy od tego, czy podejmiemy ryzyko postawy maksymalnie życzliwej, przy której interpretujemy tę teorię $w$ jej najsilniejszej, a więc najtrudniejszej do skrytykowania, postaci. ${ }^{14}$

\footnotetext{
${ }^{13}$ Beнte, „Współczesna hipoteza...”, s. 244.

${ }^{14} \mathrm{Na}$ temat postawy maksymalnie życzliwej por. Kazimierz JоркоwsкI, Wspólnoty uczonych, paradygmaty i rewolucje naukowe, Realizm. Racjonalność. Relatywizm t. 22, Wyd. UMCS, Lublin 1990, s. 12-15, http://tiny.pl/v3d5 oraz Kazimierz JoDKowsKi, Metodologiczne aspekty kontrowersji ewolucjonizm-kreacjonizm, Realizm. Racjonalność. Relatywizm t. 35, Wyd. UMCS, Lublin 1998, s. 14-15, http://tiny.pl/b9m2.
} 


\section{Czy mini-ID ma konsekwencje, dotyczące nadnaturalnego projektanta?}

Sober posiadanie konsekwencji zdefiniował na nowo. Teoria ID ma konsekwencje, dotyczące istnienia nadnaturalnego projektanta, jeśli w koniunkcji z kilkoma dodatkowymi założeniami pociąga tezę o istnieniu lub nieistnieniu tego nadnaturalnego projektanta, przy czym te dodatkowe założenia są prawdziwe i istnieją dobre powody, by w tę prawdziwość wierzyć. Sober upiera się dalej, że taką charakterystykę posiadają takie założenia jak ,niektóre umysły są nieredukowalnie złożone”, „Wszechświat nie jest wieczny” oraz ,przyczyna poprzedza w czasie skutek". Zwłaszcza to ostatnie założenie jest dziwne, skoro wcześniej w artykule sam przytaczał słowa Behe'ego o podróżach w czasie. Pozostałe założenia również nie są pewne. Są wątpliwe, jeśli nie fałszywe lub wręcz pozbawione sensu.

\section{Czy darwinizm jest neutralny religijnie?}

Sober pokazał, że darwinizm nie pociąga tezy ani o istnieniu, ani o nieistnieniu istot nadprzyrodzonych. Nie znaczy to jednak, jak wnioskował, że darwinizm jest neutralny wobec wszelkich religii. Jeśli za Soberem przyjmiemy, że teoria darwinowska to dwa twierdzenia - że wszystkie organizmy pochodzą od wspólnego przodka oraz że dobór naturalny był ważną przyczyną wszystkich ${ }^{15}$ podobieństw i różnic, jakie obserwujemy wśród organizmów - to łatwo pokazać, że wpada ona w konflikt z poglądem religijnym, według którego przynajmniej za niektóre podobieństwa i różnice odpowiadają akty stwórcze Boga. A ten ostatni pogląd występował i występuje tradycyjnie w głównych

\footnotetext{
${ }^{15} \mathrm{~W}$ tekście Sobera słowa „wszystkich” w tym miejscu nie ma, ale myślę, że oddaje ono jego intencje. Mnie słowo to było potrzebne, by wyraźniej pokazać kontrast z poglądami religijnymi.
} 
religiach teistycznych (aczkolwiek nie we wszystkich ich odmianach i interpretacjach).

\section{Czy sprzeciw wobec naturalizmu pociąga nadnaturalizm?}

Sober popełnia w tej sprawie często spotykany błąd:

W powszechnie stosowanym podręczniku ID - Of Pandas and People [O pandach i ludziach], Percival Davis i Dean Kenyon często przeciwstawiają przyczyny „naturalne” przyczynom ,inteligentnym”. Oznacza to, że wspominani przez nich inteligentni projektanci mają charakter nadnaturalny.

Ale naturalizm jest pojęciem wieloznacznym i może być rozumiany jako odwoływanie się jedynie do przyczyn naturalnych, czyli bezosobowych i nieinteligentnych, przeciwstawianych przyczynom nienaturalnym (inteligentnym i celowym), a nie przyczynom nadprzyrodzonym. ${ }^{16}$ Sober nie zauważył po prostu wielu wyjaśnień tego rodzaju:

mówi się nam, że nauka bada przyczyny naturalne, natomiast wprowadzanie Boga jest odwoływaniem się do przyczyn nadnaturalnych. Ale to niewłaściwe przeciwstawienie. Właściwe ma miejsce między niekierowanymi przyczynami naturalnymi z jednej strony a inteligentnymi przyczynami z drugiej. Przyczyny inteligentne mają skutki, których niekierowane przyczyny naturalne mieć nie mogą. ${ }^{17}$

\footnotetext{
${ }^{16}$ Por. Kazimierz JodKowsкI, „Antynaturalizm teorii inteligentnego projektu”, Roczniki Filozoficzne 2006, t. 54, nr 2, s. 73 [63-76], http://tiny.p1/b9mb.

${ }^{17}$ William A. Dembski, „Introduction: Mere Creation”, w: William A. Dembski (ed.), Mere Creation. Science, Faith \& Intelligent Design, InterVarsity Press, Downers Grove, Illinois 1998, s 15 [13-30]. Por. też Thomas Woodward, Darwin Strikes Back. Defending the Science of Intelligent Design, Baker Books, Grand Rapids, Michigan 2006, s. 115 oraz William A. Dembski, Sean McDowell, Understanding Intelligent Design. Everything You Need to Know in Plain Language, Harvest House Publishers, Eugene, Oregon 2008, s. 89.
} 


\section{Konkluzja}

W polemice Sobera znaleźć można trafne spostrzeżenia - na przykład to, że nieredukowalna złożoność dotyczy podziału na części tylko na niektórych, nie na każdym, poziomie podziału. Jednak zasadniczego celu nie osiągną - nie wykazał, że teoria inteligentnego projektu wypowiada się o istnieniu nadnaturalnego projektanta. Nie wydaje się, by na drodze racjonalnej argumentacji można było zwalczyć teorię ID przez przypisanie jej tej cechy. Pozostają jednak sprawdzone już metody - orzeczenia sądowe ${ }^{18}$ oraz stosowanie Berufsverbot. ${ }^{19}$

Kazimierz Jodkowski

${ }^{18}$ John E. Jones III, „Kitzmiller v. Dover Area School District”, http://tiny.pl/b9mz.

${ }^{19}$ Por. Jerry Bergman, The Criterion: Religious Discrimination in America, Onesimus, Richfield, Minnesota 1984 oraz tenże, Slaughter of the Dissidents: The Shocking Truth about Killing the Careers of Darwin Doubters, Leafcutter Press 2008. 